\title{
AHP-UTILITY BASED MODEL FOR EVALUATING THE COMFORT OF HOUSING: A CASE STUDY OF TAIWAN
}

\author{
WU, W. C. ${ }^{*}-$ PERNG, Y. H. \\ Department of Architecture, National Taiwan University of Science and Technology \\ No.43, Keelung Rd., Sec.4, Da'an Dist., Taipei City 10607, Taiwan \\ (tel: +886-9-37703000; fax: +886-4-23801669) \\ *Corresponding author \\ e-mail: chji888.chji@msa.hinet.net \\ (Received $12^{\text {th }}$ Aug 2016; accepted $12^{\text {th }}$ Oct 2016)
}

\begin{abstract}
Buying a house for personal use is an infrequent investment for most people because of the high sales cost. Most buyers only make one housing purchase in their lives, most often for personal use. Real estate developers evaluate decisions for housing development projects often according to marketand sales-oriented factors. In addition to the fact that the industry involves fierce competition, real estate developers frequently neglect using healthy building materials and comfortable interior designs, focusing instead on a luxurious building facade to attract customers and the use of high-quality imported materials in the common spaces inside the building. To identify the factors affecting the comfort of living in houses and satisfy customer demands, this study combined two decision theories, the analytical hierarchy process and utility theory, to develop a customer health-oriented housing comfort assessment model. This model can be used to assess and compare the quality of living of various houses, providing housing agents with an evaluation tool that accounts for both sales and customer health that can be used in the evaluation process before a house is introduced to customers. Thus, the effectiveness of decision-making can be improved and the risk of investment reduced.
\end{abstract}

Keywords: housing for personal use, real estate development, interior design, analytical hierarchy process $(A H P)$, utility theory

\section{Introduction}

The building industry is a project-oriented industry (Voordijk et al., 2000), and project types (e.g., planning and design, construction, and vendor alliances) often vary among different building projects ( $\mathrm{Li}$ and O'Brien, 1995). Because of the heterogenic construction process, the production and construction process in the building industry involve higher-than-normal risk compared with that in the general manufacturing sector, characterized by regularity and homogeneity. Furthermore, public building construction mostly involves customized products that are characterized by clear product features and specifications desired by customers (Kornelius and Wamelink, 1998); construction companies can simply adhere to the demands and specifications from owners. However, when real estate developers invest in houses, they must predict the demands of future customers, and when the housing plans do not receive customer approval, the house might not sell favorably, and housing vendors must reduce prices to attract buyers and avoid major losses. Therefore, real estate developers have much more operational risk than do construction companies that work only on a contractual basis.

Conventionally, production processes in the building industry are used to create the final houses and include services and considerations of customer satisfaction (Gruca and 
Rego, 2005; Smith and Wright, 2002). Houses are a type of product in the housing industry. To improve customer satisfaction, real estate developers generally consider relevant factors that influence sales, such as the building facade, public space planning, construction and building material costs, housing prices (Chen et al., 2012), regional environmental conditions, repairs and maintenance, and services. However, using green building materials that benefit customer health and planning comfortable spaces inside the building are frequently neglected because such considerations are not easily comprehensible for most customers and also affect interior partition, construction costs, design and planning time, and construction time and methods. Therefore, regarding project development assessment, most real estate developers continue to develop and evaluate houses conventionally, neglecting factors that can facilitate improving the comfort of interior spaces.

The high concentration of $\mathrm{CO}_{2}$ in the atmosphere worldwide in recent years, which has been ineffectively controlled, has already severely affected the environment (Bilgili, 2012), causing global climate changes and severe disasters caused by the climate (Caillaud et al., 2012). Environmental pollution is caused by the economic development of all countries and the destruction produced by humans. Thus, protecting the environment is a common responsibility of all people worldwide; only if countries carefully investigate the causes of pollution and create effective control and management policies can energy consumption and $\mathrm{CO}_{2}$ emissions be lowered. However, no consensus regarding the reason for environmental problems has been reached, primarily because national economic interests and industrial and commercial economic interests are affected, but also because the habits in daily life will be influenced; these are still the reasons why various countries have been unable to attain $\mathrm{CO}_{2}$ emission reduction agreement goals. Consequently, future environmental damage, greenhouse gas emissions, and climate change-induced catastrophes might severely harm human life and property.

The global greenhouse effect, combined with the heat island effect in Taiwan, caused the hottest temperature in 100 years to be recorded in Taiwan in September 2014. Taiwan, an island with high $\mathrm{CO}_{2}$ emissions, possesses numerous highly polluting industries (e.g., thermal power production plants, chemical plants, oil refineries, steel plants, shipbuilding sites, cement plants, and industrial science parks) that require large amounts of natural energy sources such as oil, coal, and natural gas. These industries are the main cause of excessive pollution, hindering the resolution of air pollution and $\mathrm{CO}_{2}$ emission problems. In addition to the aforementioned pollution sources, vehicles emit large quantities of waste gas daily in Taiwan. Among Taiwan's 111.54 million kiloliters of oil equivalent energy consumption in 2012, the energy and industrial, transport, agricultural, service, and residential sectors accounted for $45.25 \%, 11.89 \%, 0.89 \%$, $11.04 \%$, and $10.88 \%$, respectively (Ministry of Economic Affairs, ROC, 2012). Most of the residential sector energy consumption is caused by construction machinery and the electricity and generator oil consumed during the building process. The residential sector also creates severe air and waste pollution.

According to the aforementioned descriptions, the severe air pollution problems in Taiwan and the global greenhouse and heat island effects that have caused existing problems and poor overall environmental quality in the country are evident. Currently, the goal of improving the comfort of home environments can be achieved only through the planning and design of living spaces, in which real estate developers should 
consider the health of homebuyers and corporate social responsibility, thus establishing a corporate image. Therefore, to consider the interests of both real estate developers and customers and to lower investment risks, an objective assessment model must be established to facilitate decision-making. Conventional economic analysis methods and market surveys used by general real estate developers cannot be applied to assess the risks that the aforementioned factors, which are intangible and not easily quantified, might produce. In addition, housing vendors have long relied almost entirely on the subjective opinions of decision-makers as a basis for assessing project development (Ozsoy et al., 1996). However, this type of decision-making lacks an objective correction mechanism. Thus, in this study, we applied the analytical hierarchy process (AHP) and utility theory to establish an assessment model that enables decision-makers to make objective and rational decisions and that can be used to plan housing projects that more closely match customer demands.

\section{AHP-utility-based model framework}

The decision assessment model established in this study has practical application value. The overall research framework content can be divided into (1) model development and (2) model application. The development of the model, which combines the features of the two multicriteria decision making (MCDM) models, AHP and utility theory, is summarized as follows:

(1) Relevant literature on factors that influence housing quality was reviewed as a foundation for this study, and the criteria that corresponded to the requirements of the study model were further determined.

(2) After the criteria for the assessment questions were determined, a hierarchy among the assessment factors was established, and we ensured that each criterion was independent.

(3) Regarding the design, distribution, and recovery of the AHP questionnaires, AHP calculation formulae were used to obtain the relative size weighting values of the criteria.

(4) If the recovered AHP questionnaires passed consistency tests, then the questionnaire data was considered valid. The criteria included the following: the consistency index $(\mathrm{CI})$ was $\mathrm{CI} \leq 1$ and the consistency ratio (CR) was $\mathrm{CR} \leq 0.1$.

(5) The utility function of each factor was established, the quantization interval value was defined (convenient expression was the main consideration), and the effect values of the maximal, minimal, and threshold points were defined to serve as the utility function for solving each assessment factor.

(6) From the relative weighting value and utility value of each assessment factor, the expected utility value (EUV) was obtained, completing the establishment of the assessment model.

The AHP-utility-based model is highly adaptive and convenient; the application of the model is summarized as follows:

(1) The model can be used to assess the interior comfort of single households, as a tool for self-review provided to customers when purchasing houses, or as a reference for real estate developers and sales companies when establishing prices.

(2) The model can be applied to assess the interior comfort of overall housing 
development projects, providing a reference for design, planning, and modification as well as a reference for real estate developers considering overall sales establishing prices.

(3) From the obtained relative weighting values, the importance of each assessment factor relative to other factors and significant influential relationships can be understood.

(4) From the utility values of each assessment factor, the relationship by which the factors influence the overall EUV can be understood.

\section{Literature review}

\section{Analytical hierarchy process}

The AHP, a MCDM model proposed by Saaty (1980), is commonly applied for decision analysis in management and other fields. Related research includes that on the maintenance selection problem (Bertolini and Bevilacqua, 2006) and redeveloping derelict public buildings (Hsueh et al., 2013). After the AHP was used to obtain data regarding the event to be evaluated through the questionnaires, the data that passed the consistency tests were further used to obtain the relative weighting values of each criterion through AHP calculations. Thus, the structured decision analysis method for the problem we investigated is provided.

\section{Utility theory}

In 1738, Daniel Bernoulli proposed utility theory, which is used to express the preferences and relative risk attitudes of people. A complex risk of uncertainty exists in decisions; therefore, the advantage of the utility theory is that it provides decision-makers with a quantified analysis mode that facilitates enhancing the objectivity of decisions. Relevant utility theory-related research in various fields includes evaluating household energy conservation performance (Hsueh, 2012) and build-operate-transfer projects (Yan et al., 2011). Regarding the application of the utility theory, we first defined the respective linear utility function of each criterion to convert each assessment situation into a quantified utility value.

\section{Model description}

\section{Developing the initial criteria and hierarchy}

The purpose of housing projects is to improve quality of living and customer satisfaction with the goal of creating comfortable living spaces. According to Benett (1993), the planning and design of houses must satisfy the demands of customers. For example, the price of housing can be reduced to attract ordinary consumers with relatively low incomes, increasing the attractiveness of housing projects (Ziara and Ayyub, 1999). However, in addition to the fact that the planning and design of houses is competitive, Altas and Ozsoy (1996) indicated that residents increasingly emphasize problems with housing environmental quality. Therefore, the environmental conditions near houses are also a crucial factor influencing the attractiveness of housing projects. In their study on an assessment model for housing quality, Ozsoy et al. (1996) indicated that to increase residents' satisfaction, the comfort of the outdoor environment should be 
emphasized in housing planning and design, and thus, the pollution level of the surrounding environment should also be considered. Furthermore, in addition to housing conditions and environment, the brand established by real estate developers over time is a crucial factor that can create customer confidence in houses. For example, Turpin (1995) indicated that the company brands of Japanese companies, cultivated over time by adopting customer satisfaction as an operational objective, were quality guarantees for the consumers; this guarantee of quality is an aspect in which Japanese companies differ from European and North American companies (Turpin, 1995).

According to the aforementioned discussion, we compiled three assessment dimensions for creating comfortable living spaces and satisfying the demands of housing customers: product features, pollution level, and brand awareness. To satisfy living space comfort demands, the relevant criteria in the product feature dimension include double-skin facades (Roth et al., 2007), solar energy application (Trappey et al., 2012), shading devices (Kotey et al., 2009), and ventilation designs. Relevant criteria that should be considered in the pollution level dimension are air pollution, water pollution, noise pollution, and soil pollution in the vicinity. The criteria that should be considered in the brand awareness dimension include corporate social responsibility, service, and maintenance. Figure 1 shows a comprehensive hierarchy of each criterion in the three assessment dimensions.

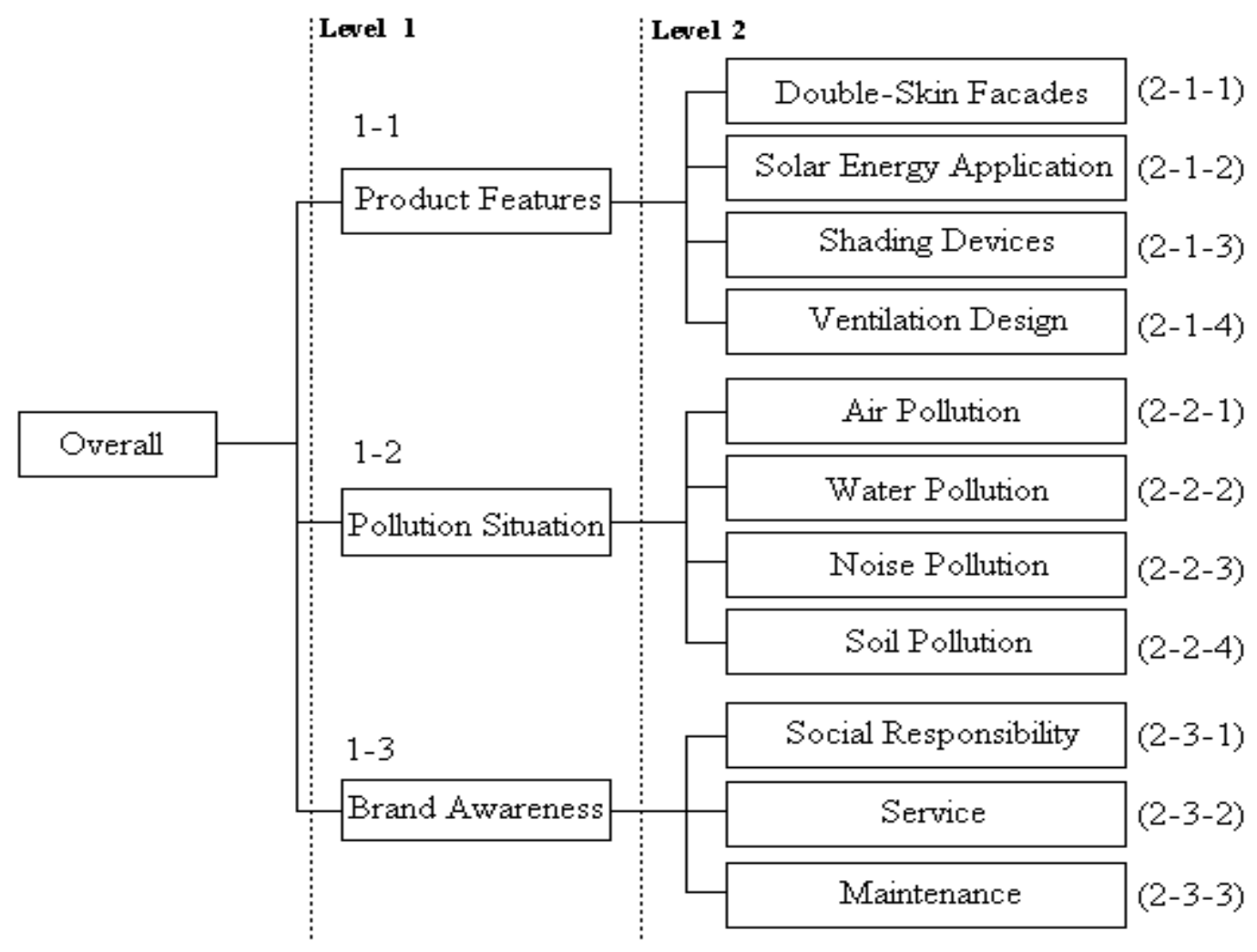

Figure 1. Hierarchy of criteria 


\section{Weighting value of each criterion}

We distributed 100 AHP questionnaires and recovered 52 valid questionnaires, the data from which were used to calculate the relative weighting values of the three assessment dimensions (Tables 1-4). We averaged the data values obtained from the valid questionnaires to compare ratios of each criterion presented in the tables. Table 5 lists the weighting values of each criterion.

Table 1. Weighting value of overall

Comparisons of Product Features, Pollution situation and Brand Awareness()

\begin{tabular}{l|l|l|l}
\hline Criteria & Product Features & Pollution situation & Brand Awareness \\
\hline Product Features & 1 & 0.742 & 1.571 \\
\hline Pollution situation & 1.348 & 1 & 1.545 \\
\hline Brand Awareness & 0.636 & 0.647 & 1 \\
\hline Eigenvector & 0.342 & 0.416 & 0.242 \\
\hline
\end{tabular}

Consistency Index(C.I.) $=0.006$, Consistency Ratio(C.R. $)=0.010$

Table 2. Weighting value of product features

Comparisons of Double-Skin Facades(2-1-1), Solar energy application(2-1-2), Shading Devices(2-1-3) and Ventilation Design(2-1-4)

\begin{tabular}{l|l|l|l|l}
\hline Criteria & $(2-1-1)$ & $(2-1-2)$ & $(2-1-3)$ & $(2-1-4)$ \\
\hline$(2-1-1)$ & 1 & 1.581 & 2.115 & 0.856 \\
\hline$(2-1-2)$ & 0.633 & 1 & 0.272 & 0.246 \\
\hline$(2-1-3)$ & 0.473 & 3.671 & 1 & 0.568 \\
\hline$(2-1-4)$ & 1.169 & 4.057 & 1.759 & 1 \\
\hline Eigenvector & 0.292 & 0.102 & 0.224 & 0.382 \\
\hline
\end{tabular}

Consistency Index(C.I.)=0.074, Consistency Ratio(C.R.) $=0.083$

Table 3. Weighting value of Pollution situation

Comparisons of Air pollution(2-2-1), Water pollution (2-2-2), Soil pollution (2-2-3) and Noise pollution(2-2-4)

\begin{tabular}{l|l|l|l|l}
\hline Criteria & $(2-2-1)$ & $(2-2-2)$ & $(2-2-3)$ & $(2-2-4)$ \\
\hline$(2-2-1)$ & 1 & 2.105 & 0.497 & 0.914 \\
\hline$(2-2-2)$ & 0.475 & 1 & 3.091 & 1.208 \\
\hline$(2-2-3)$ & 0.494 & 0.324 & 1 & 2.388 \\
\hline$(2-2-4)$ & 0.523 & 0.828 & 0.419 & 1 \\
\hline Eigenvector & 0.314 & 0.305 & 0.208 & 0.173 \\
\hline
\end{tabular}

Consistency Index(C.I.)=0.69, Consistency Ratio(C.R.) $=0.077$ 
Table 4. Weighting value of overall

Comparisons of Social responsibility(2-3-1), Maintenance(2-3-2) and service(2-3-3)

\begin{tabular}{l|l|l|l}
\hline Criteria & $(2-3-1)$ & $(2-3-2)$ & $(2-3-3)$ \\
\hline$(2-3-1)$ & 1 & 1.105 & 0.415 \\
\hline$(2-3-2)$ & 0.905 & 1 & 0.476 \\
\hline$(2-3-3)$ & 2.408 & 2.10 & 1 \\
\hline Eigenvector & 0.238 & 0.233 & 0.529 \\
\hline
\end{tabular}

Consistency Index(C.I.) $=0.003$, Consistency Ratio(C.R.) $=0.005$

Table 5. Weighting values of criteria

\begin{tabular}{llllll}
\hline Criteria & Level (1) Wi & Sub-Criteria & Level (2) Wi & Overall $W i$ & Overall Sequence \\
\hline \multirow{3}{*}{$1-1$} & \multirow{3}{*}{0.342} & $(2-1-1)$ & 0.292 & 0.100 & 4 \\
\cline { 3 - 6 } & & $(2-1-2)$ & 0.102 & 0.035 & 10 \\
\cline { 3 - 6 } & & $(2-1-3)$ & 0.224 & 0.077 & 6 \\
\cline { 3 - 6 } & & $(2-1-4)$ & 0.382 & 0.131 & 1 \\
\hline \multirow{3}{*}{$1-2$} & 0.416 & $(2-2-1)$ & 0.314 & 0.131 & 1 \\
\hline & & $(2-2-2)$ & 0.305 & 0.127 & 3 \\
\hline & & $(2-2-3)$ & 0.208 & 0.087 & 5 \\
\hline \multirow{3}{*}{$1-3$} & 0.242 & $(2-2-4)$ & 0.173 & 0.072 & 7 \\
\hline & & $(2-3-1)$ & 0.238 & 0.058 & 8 \\
\hline & & $(2-3-3)$ & 0.233 & 0.056 & 9 \\
\hline
\end{tabular}

The sequence of the weighting values of each criterion in Table 5 shows that the five criteria of ventilation design, air pollution, maintenance, water pollution, and double-skin facades significantly influenced the comfort of housing spaces. Among these criteria, ventilation design, double-skin facades, and maintenance increased the design, human resources, and construction costs of real estate developers. In addition, air and water pollution are regional environmental pollution problems; therefore planning and design as well as the use of green building materials and novel construction methods must be emphasized in developing housing projects and selecting a region with favorable environmental conditions.

\section{Utility function of each criterion}

In this study, we explored the comfort of housing spaces to achieve effective decision-making regarding housing project development and customer expectations. Therefore, a linear utility function was adopted and defined as $u_{i}\left(y_{i}\right)=A y_{i}+B$; to apply the utility theory for establishing the assessment model, the utility function of each criterion must first be determined. Every housing project has distinct conditions and situation; thus, each criterion will have a dissimilar assessment status, directly 
influencing the parameter values $(A$ and $B)$ of the utility function. Thus, the parameter values in the utility function of each criterion must be determined before calculating the utility value of each criterion. The calculation of $A$ and $B$ is described as follows:

(1) In the assessment scope of each criterion $\left(y_{L}-y_{u}\right), y_{u}$ is the highest value and $y_{L}$ is the lowest value. The assessment scope is defined according to the risk assumed by decision-makers and personal subjective preferences.

(2) The optimal utility value in $\left(y_{L}-y_{u}\right)$ is $y_{m}$, and $u_{i}\left(y_{m}\right)=1$. The threshold point is $y_{T}$, and the turning point between positive and negative utility is $u_{i}\left(y_{T}\right)=0$.

(3) Thus, equation (2) yields $u_{i}\left(y_{T}\right)=A \times y_{T}+B=0, \quad B=-A y_{T}$, and thus, the relationship between A and B can be obtained:

$$
u_{i}\left(y_{m}\right)=A \times y_{m}+B=1, \quad A=1 /\left(y_{m}-y_{T}\right) .
$$

(4) The utility function of each criterion can be expressed as $u_{i}\left(y_{i}\right)=\left[1 /\left(y_{m}-y_{T}\right)\right] \times y_{i}-y_{T} /\left(y_{m}-y_{T}\right)$

(5) For each criterion, the utility function can be used to convert the assessment situation into a quantified utility value.

\section{Weighting value, utility value, and expected utility value}

Although the size relationship among the relative weighting values obtained from each criterion only describes the relative influence of each criterion on the living space comfort in this study, the product of the relative weighting value $\left(W_{i}\right) *$ utility value $\left(u_{r i}\right)$ of each criterion is the EUV, a quantified assessment mode that can be used to compare size. Table 6 presents the relevant definitions used in this study and the obtained weighting value, utility value, and utility function of each criterion. The EUV equation is as follows:

$$
\mathrm{EUV}=\sum_{i=1}^{n}\left(u_{r i} \times W_{i}\right)
$$

Table 6. weighting value, utility value and EUV

\begin{tabular}{lllllllll}
\hline Criteria & $\left(W_{i}\right) * 100 \%$ & $y_{L}$ & $y_{u}$ & $y_{T}$ & $y_{m}$ & Utility Function $\left(u_{r i}\right)$ & Worst & Optimal \\
\hline$(2-1-1)$ & 10 & 0 & 100 & 50 & 100 & $u(y)=0.02 y-1$ & -10 & 10 \\
\hline$(2-1-2)$ & 3.5 & 0 & $100 \%$ & 50 & 100 & $u(y)=0.02 y-1$ & -3.5 & 3.5 \\
\hline$(2-1-3)$ & 7.7 & 0 & $100 \%$ & 50 & 100 & $u(y)=0.02 y-1$ & -7.7 & 7.7 \\
\hline$(2-1-4)$ & 13.1 & 0 & 100 & 60 & 100 & $u(y)=0.025 y-1.5$ & -19.65 & 13.1 \\
\hline
\end{tabular}




\begin{tabular}{lllllllll}
\hline$(2-2-1)$ & 13.1 & 200 & $0(\mathrm{PSI})$ & 60 & 0 & $u(y)=-0.017 y+1$ & -31.44 & 13.1 \\
\hline$(2-2-2)$ & 12.7 & 100 & $0 \%$ & 30 & 0 & $u(y)=-0.014 y+0.4$ & -12.7 & 5.08 \\
\hline$(2-2-3)$ & 8.7 & 140 & $0 \mathrm{~dB}$ & 50 & 0 & $u(y)=-0.02 y+1$ & -15.66 & 8.7 \\
\hline$(2-2-4)$ & 7.2 & 100 & 0 & 30 & 0 & $u(y)=-0.014 y+0.4$ & -7.2 & 2.88 \\
\hline$(2-3-1)$ & 5.8 & $0 \%$ & 100 & 60 & 100 & $u(y)=0.025 y-1.5$ & -8.7 & 5.8 \\
\hline$(2-3-2)$ & 5.6 & $0 \%$ & 100 & 60 & 100 & $u(y)=0.025 y-1.5$ & -8.4 & 5.6 \\
\hline$(2-3-3)$ & 12.8 & $0 \%$ & 100 & 60 & 100 & $u(y)=0.025 y-1.5$ & -19.2 & 12.8 \\
\hline \multicolumn{7}{l}{ Expected utility value (EUV) } \\
\hline
\end{tabular}

The weighting values $\left(W_{i}\right)$ in Table 6 were multiplied by $100 \%$ for convenient calculation and use. Regarding the threshold point definitions, the fuzzy range of air pollution was 0-200 PSI, because an air pollution level exceeding 200 PSI causes people to experience discomfort; a level of 51-100 PSI indicates mild pollution, and the air pollution threshold point was set to 60 PSI in this study. Regarding noise pollution, among the range of $0-140 \mathrm{~dB}$ generally heard by the human ear, people perceive $50 \mathrm{~dB}$ and below to be comfortable; sounds of 50-70 dB cause slight discomfort, and sounds exceeding $70 \mathrm{~dB}$ cause anxiety and trigger various other symptoms (Environmental Protection Administration, Executive Yuan, 2014). Therefore, the noise pollution threshold point was set to $50 \mathrm{~dB}$ in this study. As shown by the calculation results in Table 6, the worst situation EUV was -141.15 and the optimal situation EUV was 88.26.

\section{Case study}

By calculating the weighting value and utility value of each criterion and the overall expected utility value, using the overall EUV, and applying the AHP-utility decision-making model, we obtained quantified values and compared their sizes. The values can be used by decision-makers as an auxiliary reference. In this study, we applied the model to three cases from Central Taiwan. The assessments were as follows:

(1) The assessment results of each criterion in Case 1 revealed that except for the relatively favorable situation regarding noise and soil pollution, the conditions for the other criteria merely approached the threshold point. Table 7 shows the overall living space comfort assessment values $\left(y_{i}\right)$ of each criterion.

(2) Cases 2 and 3 involved assessments of development projects conducted by the same company in the same region. The case situations are identical, except that in Case 3, the planning of double-skin facades was not considered and the ventilation design involved no appropriate equipment plan. Table 7 shows the overall living space comfort assessment values $\left(y_{i}\right)$ of each criterion for Cases 2 and 3.

Regarding the overall expected utility aspect of the housing comfort assessment results in Cases 1-3, the building facade and ventilation design facilitated improving the living space comfort in Taiwan, which is located in a subtropical region. In addition, based on the assessment results for Cases 2 and 3, the EUV of Case 2 was nearly double that of Case 3. The model application assessment results for Cases 1-3 are shown in Fig. 2. 
Table 7. Assessment results for Cases 1-3

\begin{tabular}{lllllllll}
\hline & $\left(W_{i}\right)$ & Case 1 & \multicolumn{3}{c}{ Case 2 } & \multicolumn{2}{c}{ Case 3 } \\
\cline { 3 - 8 } Criteria & & $\left(y_{i}\right)$ & $\left(u_{r i}\right) *\left(W_{i} \%\right)$ & $\left(y_{i}\right)$ & $\left(u_{r i}\right) *\left(W_{i} \%\right)$ & $\left(y_{i}\right)$ & $\left(u_{r i}\right) *\left(W_{i} \%\right)$ \\
\hline$(2-1-1)$ & 0.100 & 50 & 0 & 100 & 10 & 50 & 0 \\
\hline$(2-1-2)$ & 0.035 & 50 & 0 & 80 & 2.1 & 80 & 2.1 \\
\hline$(2-1-3)$ & 0.077 & 50 & 0 & 80 & 4.62 & 80 & 4.62 \\
\hline$(2-1-4)$ & 0.131 & 60 & 0 & 80 & 6.55 & 60 & 0 \\
\hline$(2-2-1)$ & 0.131 & 0 & 0 & 40 & 4.19 & 40 & 4.19 \\
\hline$(2-2-2)$ & 0.127 & 0 & 0 & 20 & 1.52 & 20 & 1.52 \\
\hline$(2-2-3)$ & 0.087 & 0 & 8.7 & 30 & 3.48 & 30 & 3.48 \\
\hline$(2-2-4)$ & 0.072 & 0 & 2.88 & 20 & 0.864 & 20 & 0.864 \\
\hline$(2-3-1)$ & 0.058 & 60 & 0 & 80 & 2.9 & 80 & 2.9 \\
\hline$(2-3-2)$ & 0.056 & 60 & 0 & 80 & 2.8 & 80 & 2.8 \\
\hline$(2-3-3)$ & 0.128 & 60 & 0 & 80 & 6.4 & 80 & 6.4 \\
\hline$($ EUV $)$ & & 11.58 & 45.42 & & 28.87 & \\
\hline
\end{tabular}

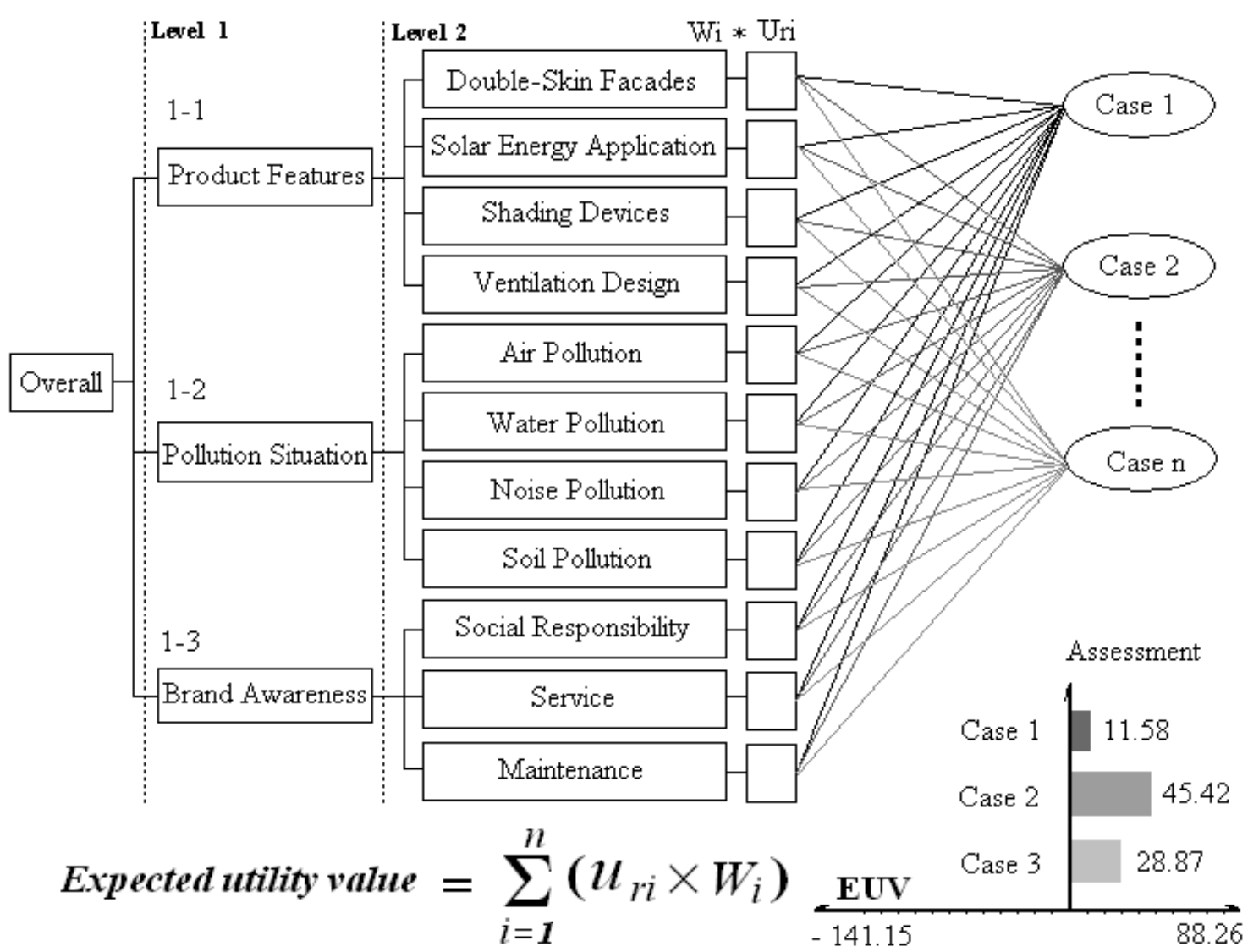

Figure 2. Schematic of the assessment results for Cases 1-3 


\section{Conclusion}

Ensuring the comfort of living spaces is the basic cognition and responsibility of real estate developers. For homebuyers, such comfort facilitates quality of life in the home and is also a fundamental right. However, because of cost and market competition factors, real estate developers frequently disregard planning and designing high-quality, comfortable living spaces. The results of this study revealed that regarding the influences on housing space comfort, corporate image as well as planning and design must be considered in addition to regional environment. Planning and design, green building materials, and novel construction methods can be adopted to overcome the congenital problem of poor environmental quality. Thus, the comfort of living spaces can be enhanced.

Taiwan is located in a subtropical region and has developed industries; moreover, residents extensively use cars and scooters daily, creating excessive energy consumption and large amounts of warm gas emissions, which cause severe air pollution and heat island effects. Therefore, the extensive use of air conditioning and the increasing use of electricity are serious unresolved problems in Taiwan in the summer. Regarding an effective solution for the problems of housing space comfort in Taiwan and household energy consumption, if real estate developers can comprehensively consider and attain high quality in the planning and design stage of construction, then the quality of living can be improved and environmental pollution can be reduced. Otherwise, subsequently improving housing spaces will result in construction waste and waste gas and hot gas emissions that influences neighboring households. The results of this study indicate that the essential question of residential spaces is overlooked because real estate developers lack social responsibility. In addition, homebuyers lack professional knowledge, causing them to be deceived in the long term. The AHP-utility decision-making model can provide real estate developers and homebuyers with a tool for assessing the comfort of housing spaces, facilitating an overall increase in housing quality in Taiwan.

\section{REFERENCES}

[1] Bennett, J. (1993): Japan's building industry: the new model. - Construction Management and Economics 11: 3-17.

[2] Bertolini, M., Bevilacqua, M. (2006): A combined goal programming-AHP approach to maintenance selection problem. - Reliability Engineering \& System Safety 91: 839-848.

[3] Bilgili, F. (2012): The impact of biomass consumption on $\mathrm{CO}_{2}$ emissions: cointegration analyses with regime shifts. - Renewable and Sustainable Energy Reviews 16: 5349-5354.

[4] Caillaud, S., Kalampalikis, N., Flick, U. (2012): The social representations of the Bali climate conference in the French and German media. - Journal of Community \& Applied Social Psychology 22: 363-378.

[5] Chen, M.C., Chang, C.O., Yang, C.Y., Hsieh, B.M. (2012): Investment demand and housing prices in an emerging economy. - Journal of Real Estate Research 34: 345-373.

[6] Environmental Protection Administration, Executive Yuan, Taiwan. (2014): Noise Control. - http://ncs.epa.gov.tw/BB/B-04-01.htm.

[7] Gruca, T.S., Rego, L.L. (2005): Customer satisfaction, cash flow, and shareholder value. Journal of Marketing 69: 115-130.

[8] Hsueh, S.L. (2012): A fuzzy utility-based multi-criteria model for evaluating households' energy conservation performance: a Taiwanese case study. - Energies 5: 2818-2834. 
[9] Hsueh, S.L., Lee, J.R., Chen, Y.L. (2013): DFAHP multicriteria risk assessment model for redeveloping derelict public buildings. - International Journal of Strategic Property Management 17: 333-346.

[10] Korneliu, L., Wamelink, J.W.F. (1998): The virtual corporation learning from construction. - Supply Chain Management 3: 193-202.

[11] Kotey, N.A., Wright, J.L., Barnaby, C.S., Collins, M.R. (2009): Solar gain through windows with shading devices: simulation versus measurement. - ASHRAE Transactions 115: $18-30$.

[12] Li, C., O'Brien, D. (2001): A quantitative analysis of relationships between product types and supply chain strategies. - International Journal of Production Economics 73: 29-39.

[13] Ministry of Economic Affairs, Taiwan. (2012): Energy Statistics Hand Book. - Taipei: Ministry of Economic Affairs, Taiwan.

[14] Ozsoy, A., Altas, N.E., Ok, V., Pulat, G. (1996): Quality assessment model for housing: a case study on outdoor spaces in Istanbul. - Habitat International 20: 163-173.

[15] Roth, K., Lawrence, T., Brodrick, J. (2007): Double-skin façades. - ASHRAE Journal 49: 70-73.

[16] Saaty, T.L. (1980): The Analytical Hierarchy Process: Planning, Priority Setting, Resource Allocation. - New York: McGraw-Hill Book Co.

[17] Smith, R.E., Wright, W.F. (2004): Determinants of customer loyalty and financial performance. - Journal of Management Accounting Research 6: 183-205.

[18] Trappey, A.J.C., Trappey, C.V., Lin, G.Y.P., Chang, Y.S. (2012): The analysis of renewable energy policies for the Taiwan Penghu island administrative region. - Renewable and Sustainable Energy Reviews 16: 958-965.

[19] Turpin, D.V. (1995): Japanese approaches to customer satisfaction: some best practices. Long Range Planning 28: 84-90.

[20] Voordijk, H., Haan, J., Joosten, G.J. (2000): Changing governance of supply chains in the building industry: a multiple case study. - European Journal of Purchasing \& Supply Management 6: 217-225.

[21] Yan, M.R., Pong, C.S., Lo, W.: Utility-based multicriteria model for evaluating BOT projects. - Technological and Economic Development of Economy 17: 207-218.

[22] Ziara, M.M., Ayyub, B.M. (1999): Decision analysis for housing-project development. Journal of Urban Planning and Development 125: 68-85. 